\title{
Adult height and cryptogenic fibrosing alveolitis: a case-control study using the UK General Practice Research Database
}

\author{
Richard Hubbard, Andrea Venn
}

\begin{abstract}
Background-The reasons why cryptogenic fibrosing alveolitis has emerged as a new clinical entity during the second half of the 20th century are unclear. Some environmental exposures have been identified as potential risk factors including occupational dust, cigarette smoking and antidepressants, but there have been no studies of the role of early life exposures. Since adult height reflects, in part, early life experience, we have examined the relation between adult height and the risk of cryptogenic fibrosing alveolitis.

Methods-A case-control study of 569 cases and 3669 age, sex, and community matched controls drawn from the UK General Practice Research Database was undertaken.

Results-Evidence was found of an inverse association between quintile of height and cryptogenic fibrosing alveolitis (odds ratio (OR) per increase in height quintile $0.93,95 \%$ CI 0.86 to 0.99 ). This association was not diminished by adjustment for smoking status (OR $0.93,95 \%$ CI 0.87 to 1.00 ), but some minor attenuation did occur after adjustment for oral corticosteroid use (OR $0.94,95 \%$ CI 0.88 to 1.02). There was a significant interaction with sex such that the effect of height was strong in women (OR $0.85,95 \% \mathrm{CI} 0.75$ to 0.97 ) and absent in men (OR $1.00,95 \%$ CI 0.91 to 1.09 ).

Conclusions-These findings raise the important in determining the lifetime risk of developing cryptogenic fibrosing alveolitis.
\end{abstract}

Respiratory Medicine,

University of

Nottingham,

Nottingham, UK

R Hubbard

A Venn

Correspondence to:

Dr R Hubbard, Division of

Respiratory Medicine, City

Hospital, Nottingham

NG5 1PB, UK

email: Richard.Hubbard@

Nottingham.ac.uk

Received 11 April 2000 Returned to authors 26 May 2000

Revised version received

12 June 2000

Accepted for publication

26 June 2000

(Thorax 2000;55:864-866)

Keywords: cryptogenic fibrosing alveolitis; adult height; early life experience; UK General Practice Research Database

The registered mortality from cryptogenic fibrosing alveolitis has increased markedly during the second half of the 20th century ${ }^{12}$ and the reasons for this are not clear. There is evidence from epidemiological studies that occupational dust exposures, ${ }^{3-6}$ cigarette smoking, ${ }^{47}$ and antidepressant use ${ }^{8}$ may be risk factors for the disease, but there have been no studies on the importance of early life experience. Adult height has consistently been shown to have an inverse association with all-cause mortality and mortality from respiratory disease, and this effect has generally been interpreted as reflecting the importance of early life events on long term health. ${ }^{910}$ To investigate whether early life events may be important in the lifetime risk of cryptogenic fibrosing alveolitis, we have determined the association between adult height and cryptogenic fibrosing alveolitis in a population based case-control study using data from the UK General Practice Research Database (GPRD).

\section{Methods}

Our subjects consisted of 890 cases of cryptogenic fibrosing alveolitis and 5884 age, sex, and community matched controls which have been described elsewhere. ${ }^{11}$ Briefly, cases were identified using the GPRD, which is the largest primary care population database in the $\mathrm{UK}^{12}$ and includes data from over seven million patients. Cases were defined as having cryptogenic fibrosing alveolitis if a diagnosis of the condition was recorded anywhere in the GPRD record and controls were matched by sex and general practice. We have previously established that the diagnosis of cryptogenic fibrosing alveolitis in the GPRD appears to be accurate. ${ }^{11}$ Cases and controls with a recorded diagnosis of any connective tissue disease were excluded from the analysis since connective tissue disease is a strong risk factor for cryptogenic fibrosing alveolitis and may be a cause of lost height.

Data on height and weight before the first 
Table 1 Distribution of men and women by quintile of height

\begin{tabular}{lllllll}
\hline Height quintile & $\begin{array}{l}\text { Height range for } \\
\text { women }(\mathrm{cm})\end{array}$ & $\begin{array}{l}\text { Female cases } \\
(n=214)\end{array}$ & $\begin{array}{l}\text { Female controls } \\
(n=1438)\end{array}$ & $\begin{array}{l}\text { Height range for } \\
\text { men }(\mathrm{cm})\end{array}$ & $\begin{array}{l}\text { Male cases } \\
(n=355)\end{array}$ & $\begin{array}{l}\text { Male controls } \\
(n=2231)\end{array}$ \\
\hline 1 (shortest) & $122-154$ & $58(27 \%)$ & $273(19 \%)$ & $125-167$ & $101(28 \%)$ & $563(25 \%)$ \\
2 & $155-157$ & $62(29 \%)$ & $361(25 \%)$ & $168-171$ & $49(14 \%)$ & $335(15 \%)$ \\
3 & $158-161$ & $32(15 \%)$ & $221(15 \%)$ & $172-175$ & $79(22 \%)$ & $584(26 \%)$ \\
4 & $162-165$ & $37(17 \%)$ & $344(14 \%)$ & $175-179$ & $58(16 \%)$ & $328(16 \%)$ \\
5 (tallest) & $165-188$ & $25(12 \%)$ & $239(17 \%)$ & $180-201$ & $68(19 \%)$ & $421(19 \%)$ \\
\hline
\end{tabular}

to test for possible interactions with age (in tertiles) and sex. All analyses were conducted using STATA (version 5.0) and likelihood ratio tests were used for all tests of significance.

\section{Results}

The median age of our cases at diagnosis was 71 years (interquartile range 64-78) and 553 $(62 \%)$ were men. Data were available on height for 569 cases (64\%) and $3669(63 \%)$ controls. The mean (SD) age at which height was recorded for cases was 66.4 (10.9) years and for controls was 66.4 (10.7) years. The mean (SD) recorded height for women was 159 (7) $\mathrm{cm}$ and for men was $173(7) \mathrm{cm}$. The distribution of cases and controls by height quintile are shown in table 1 . For controls with available smoking data $1016(27 \%)$ were current smokers and 2736 (73\%) were noncurrent smokers, and for cases 178 (29\%) were current smokers and 446 (71\%) were noncurrent smokers. ${ }^{11}$ There was no evidence of an association between smoking status and height for cases $(\mathrm{p}=0.3)$ or controls $(\mathrm{p}=0.8)$. We were able to calculate a body mass index for 568 cases $(64 \%)$ and 3649 controls $(62 \%)$ and found evidence of a positive association between quintile of body mass index and cryptogenic fibrosing alveolitis (odds ratio (OR) per increase in quintile of body mass index 1.08, $95 \%$ CI 1.01 to 1.16). Before the first recorded diagnosis of cryptogenic fibrosing alveolitis significantly more cases had been prescribed an oral corticosteroid than controls (325 (37\%) versus $436(7 \%), p=0.001)$. There was some evidence of an inverse association between height and exposure to oral corticosteroids for controls $(p=0.001)$ but not for cases $(p=0.2)$.

An inverse association was found between quintile of adult height and cryptogenic fibrosing alveolitis (OR per increase in height quintile $0.93,95 \%$ CI 0.86 to 0.99 ). This odds ratio was not altered by the addition of either the smoking variable (OR $0.93,95 \%$ CI 0.87 to 1.00 ) or the body mass index variable (OR

Table 2 Association between quintile of height and cryptogenic fibrosing alveolitis overall and separately for men and women

\begin{tabular}{|c|c|c|c|c|c|c|}
\hline \multirow[b]{2}{*}{ Height quintile } & \multicolumn{2}{|l|}{ Overall } & \multicolumn{2}{|l|}{ Men } & \multicolumn{2}{|l|}{ Women } \\
\hline & $\begin{array}{l}\text { Odds } \\
\text { ratio }\end{array}$ & $95 \% C I$ & $\begin{array}{l}\text { Odds } \\
\text { ratio }\end{array}$ & $95 \% C I$ & $\begin{array}{l}\text { Odds } \\
\text { ratio* }\end{array}$ & $95 \% C I$ \\
\hline 1 (shortest) & 1 & & 1 & & 1 & \\
\hline 2 & 0.77 & 0.62 to 1.09 & 0.80 & 0.53 to 1.21 & 0.67 & 0.42 to 1.07 \\
\hline 3 & 0.77 & 0.53 to 0.93 & 0.83 & 0.58 to 1.20 & 0.67 & 0.39 to 1.14 \\
\hline 4 & 0.79 & 0.57 to 1.03 & 0.98 & 0.66 to 1.47 & 0.54 & 0.32 to 0.92 \\
\hline 5 (tallest) & 0.76 & 0.54 to 0.99 & 0.92 & 0.62 to 1.37 & 0.50 & 0.27 to 0.90 \\
\hline $\begin{array}{l}\text { Odds ratio per } \\
\text { increase in } \\
\text { height quintile }\end{array}$ & 0.94 & 0.88 to 1.02 & 1.00 & 0.91 to 1.09 & 0.85 & 0.75 to 0.97 \\
\hline Test for trend & $\begin{array}{l}\mathrm{p}_{\text {trend }}= \\
0.12\end{array}$ & & $\begin{array}{l}\mathrm{p}_{\text {trend }}= \\
0.9\end{array}$ & & $\begin{array}{l}\mathrm{p}_{\text {trend }}= \\
0.012\end{array}$ & \\
\hline
\end{tabular}

^Odds ratio adjusted for oral corticosteroid exposure.
$0.93,95 \%$ CI 0.87 to 1.00$)$ to the model, but some minor attenuation did occur after adjustment for oral corticosteroid exposure (OR $0.94,95 \%$ CI 0.88 to 1.02 ) (table 2). There was no significant interaction with age $(p=0.3)$. Evidence of significant effect modification by sex was observed ( $p=0.048$, table 2$)$ such that the effect of height was strong in women (OR $0.85,95 \%$ CI 0.75 to 0.97 ) and absent in men (OR $1.00,95 \%$ CI 0.91 to 1.09 ) (table 2). In women the odds ratio for the shortest quintile compared with the tallest was 0.50 (95\% CI 0.27 to 0.90 ) (table 2 ). When height was modelled as a continuous variable for women the odds ratio per $10 \mathrm{~cm}$ increase in height was 0.74 (95\% CI 0.57 to 0.97 ).

\section{Discussion}

The results of our study provide the first evidence that there may be an inverse association between adult height and the risk of cryptogenic fibrosing alveolitis. This effect was strongest in women in whom there was a doubling in risk in the shortest quintile compared with the tallest, and a 50\% increase in risk with each $10 \mathrm{~cm}$ decrease in height.

The GPRD is the largest primary care database in the world ${ }^{12}$ and its size means that it is able to yield large numbers of cases even for uncommon conditions. However, since the data are not collected as part of a research study, the accuracy of recorded diagnoses requires confirmation and, for this reason, we have previously tested the validity of a diagnosis of cryptogenic fibrosing alveolitis in the GPRD and found it to be high. ${ }^{11}$ We did not attempt to validate height measurements but, since the error associated with these data is likely to be random, its effect will tend to dilute any association between height and disease.

The roles of bias and confounding need consideration. The main potential biases in this study are ascertainment bias and reverse causation. An ascertainment bias may explain the positive association between body mass index and cryptogenic fibrosing alveolitis, since obesity may precipitate presentation either by reducing lung volumes ${ }^{13}$ or increasing respiratory symptoms. ${ }^{14}$ It is also possible that an ascertainment bias explains the independent inverse association between height and cryptogenic fibrosing alveolitis. For example, if the symptoms associated with cryptogenic fibrosing alveolitis are more closely correlated with absolute rather than relative lung volumes, then shorter people will be more likely to present than taller people because they have smaller lungs in the first place. Reverse causation would occur if cryptogenic fibrosing alveolitis caused loss of height rather than the other way round. It has previously been suggested that 
the kyphosis caused by severe chronic obstructive pulmonary disease (COPD) may explain in part the strong inverse relation between COPD mortality and adult height. ${ }^{10} \mathrm{~A}$ direct effect of cryptogenic fibrosing alveolitis on the thoracic skeleton seems unlikely, but our cases were more likely to receive corticosteroids than controls, suggesting that some of our cases were prevalent rather than incident cases. Although exposure to oral corticosteroids is likely to be a marker of more severe or aggressive disease, it may also lead to osteoporosis. In the event, adjustment for the effect of oral corticosteroid exposure in the analysis only slightly attenuated the effect of height. Since adult socioeconomic status is associated with adult height, ${ }^{9} 10$ it is a potential confounder for the association between adult height and cryptogenic fibrosing alveolitis. In the GPRD there are no data on adult socioeconomic status so we were unable to exclude this explanation for our findings. However, adjustment for the effect of current smoking habit, which is known to be associated with socioeconomic status in the $\mathrm{UK},{ }^{15}$ had no effect on the association between height and cryptogenic fibrosing alveolitis. Furthermore, other studies have found little evidence that adult socioeconomic status explains the relation between height and cardiovascular disease. ${ }^{10} 1617$

The finding of strong effect modification by sex was unexpected. This argues against an important influence of adult socioeconomic status and also reverse causation, but would be in keeping with an ascertainment bias since women have smaller lungs than men. Women develop connective tissue diseases more commonly than men, but it seems unlikely that women with cryptogenic fibrosing alveolitis will have a diagnosis of connective tissue disease missed or not recorded more often than female general population controls. Alternatively, it may be that exposure rates to other important causes of cryptogenic fibrosing alveolitis are higher in men than in women and are masking the effect of height. Although there are few data available on risk factors for cryptogenic fibrosing alveolitis, the main ones identified to date are occupational dust exposure $^{3-6}$ and cigarette smoking, ${ }^{47}$ both of which are more common in men than in women.

Socioeconomic disadvantage in childhood has an important influence on growth and has been shown to be a predictor of adult height. ${ }^{18}$ Thus, one explanation for the inverse association between adult height and cryptogenic fibrosing alveolitis is that early life exposures such as nutrition, infection, or exposure to passive smoking increase the lifetime risk of developing chronic inflammatory diseases in general, and thereby increase the risk of developing interstitial lung diseases. Since alveoli start to develop in utero at about week 30 but continue to multiply and develop through early childhood, ${ }^{19}$ an important influence of early life experience on the subsequent risk of cryp- togenic fibrosing alveolitis seems biologically plausible. The finding that lung fibrosis is more common in shorter than in taller chrysotile miners and millers ${ }^{20}$ also raises the possibility that early and late environmental exposures may interact in determining the risk of interstitial lung disease.

In summary, the finding of an association between adult height and cryptogenic fibrosing alveolitis raises for the first time the possibility that early life exposures may influence the lifetime risk of developing this chronic inflammatory disease. However, further research is required confidently to exclude confounding by adult socioeconomic status and ascertainment bias and to establish whether this effect is restricted to women.

We would like thank Hassy Devalia and Alison Bourke from the Epidemiology and Pharmacology Information Core (EPIC) for their advice in using the General Practice Research Database. We also thank the Trent Region NHS R\&D Research Scheme for funding this project.

Funding: United Kingdom National Health Service Research and Development Project Grant.

1 Hubbard R, Johnston I, Coultas DB, et al. Mortality rates from cryptogenic fibrosing alveolitis in seven countries. Thorax 1996;51:711-6.

2 Johnston I, Britton J, Kinnear W, et al. Rising mortality from cryptogenic fibrosing alveolitis. BMF 1990;301:1017-21.

3 Scott J, Johnston I, Britton J. What causes cryptogenic fibrosing alveolitis? A case-control study of environmental exposure to dust. BMF 1990;301:1015-7.

4 Hubbard R, Lewis S, Richards K, et al. Occupational exposure to metal or wood dust and aetiology of cryptogenic fibrosing alveolitis. Lancet 1996;347:284-9.

5 Iwai K, Mori T, Yamada N, et al. Idiopathic pulmonary fibrosis. Epidemiologic approaches to occupational exposure. Am $\mathcal{F}$ Respir Crit Care Med 1994;150:670-5.

6 Baumgartner KB, Samet JM, Coultas DB, et al. Occupational and environmental risk factors for idiopathic pulmonary fibrosis: A multicenter case-control study. Am f Epidemiol 1997;45: 61 .

7 Baumgartner KB, Samet JM, Stidly CA, et al. Cigarette smoking: A risk factor for idiopathic pulmonary fibrosis. smoking: A risk factor for idiopathic pulm

8 Hubbard R, Venn A, Smith C, et al. Exposure to commonly prescribed drugs and the aetiology of cryptogenic fibrosing alveolitis: a case-control study. Am $\mathcal{F}$ Respir Crit Care Med 1998;157:743-7.

9 Leon DA, Ben-Shlomo Y. Pre-adult influences on cardiovascular disease and cancer. In: Kuh D, Ben-Shlomo Y, eds. $A$ life course approach to chronic disease epidemiology. Oxford: Oxford University Press, 1997: 45-77.

10 Leon DA, Davey Smith G, Shipley $M$, et al. Adult height and mortality in London: early life, socioeconomic confounding or shrinkage? F Epidemiol Community Health 1995;49:59 .

11 Hubbard R, Venn A, Lewis S, et al. Lung cancer and cryptogenic fibrosing alveolitis: a population based cohort togenic fibrosing alveolitis: a population based
study. Am 7 Respir Crit Care Med 2000;161:5-8.

12 Walley T, Mantgani A. The UK General Practice Research Database. Lancet 1997;350:1097-9.

13 Jenkins SC, Moxham J. The effects of mild obesity on lung Jenkins SC, Moxham J. The effects of

14 Shaheen SO, Sterne JAC, Montgomery SM, et al. Body weight, body mass index and asthma in young adults. Tho$\operatorname{rax}$ 1999;54:396-402.

5 Office for National Statistics. Living in Britain: preliminary results from the 1996 General Household Survey. D2/24. London: The Stationery Office, 1997: 16-7.

16 Yarnell JWG, Limb ES, Layzell JM, et al. Height: a risk factor for ischaemic heart disease: prospective results from the Caerphilly and Speedwell heart disease studies. Eur Heart 7 1992;13:1602-5.

17 Palmer JR, Rosenberg L, Shapiro S. Stature and the risk of myocardial infarction in women. Am f Epidemiol 1990;132: 27-32.

18 Kuh D, Power C, Blane D, et al. Social pathways between childhood and adult health. In Kuh D, Ben-Shlomo Y, eds. A life course approach to chronic disease epidemiology. Oxford: A life course approach to chronic disease epidemi

19 Jeffery PK. The development of large and small airways. Am F Respir Crit Care Med 1998;157:S174-80.

20 Becklake MR, Toyota B, Stewart M, et al. Lung structure as a risk factor in adverse pulmonary responses to asbestos exposure. Am Rev Respir Dis 1983;128:385-8. 